\title{
Contrasted transmission efficiency of Zika virus strains by mosquito species Aedes aegypti, Aedes albopictus and Culex quinquefasciatus from Reunion Island
}

\author{
Yann Gomard ${ }^{*}$, Cyrille Lebon, Patrick Mavingui ${ }^{*}$ and Célestine M. Atyame
}

\begin{abstract}
Background: Zika virus (ZIKV) is a mosquito-borne flavivirus that recently emerged in the South Pacific islands and Americas where unprecedented outbreaks were reported. Although Aedes aegypti is considered to be the main vector for ZIKV, other mosquito species have been shown to be potential vectors and differences in vector competence with respect to mosquito strain and ZIKV strain have been demonstrated. In this study we compared the vector competence of three mosquito species Aedes albopictus, Ae. aegypti and Culex quinquefasciatus from Reunion Island for three ZIKV strains.

Methods: Five mosquito strains ( 2 strains of Ae. albopictus, 1 of Ae. aegypti and 2 of $C x$. quinquefasciatus) were exposed to three ZIKV strains: one African strain (Dak84) and two Asian strains (PaRi_2015 and MAS66). The vector competence parameters (infection rate, dissemination efficiency and transmission efficiency) and viral loads were examined at 14 and 21 days post-infection.

Results: The two $C x$. quinquefasciatus strains did not become infected and were therefore unable to either disseminate or transmit any of the three ZIKV strains. Aedes albopictus and Ae. aegypti strains were poorly competent for the two Asian ZIKV strains, while both mosquito species displayed higher infection rates, dissemination and transmission efficiencies for the African ZIKV Dak84 strain. However, this African ZIKV strain was better transmitted by Ae. aegypti as compared to Ae. albopictus.
\end{abstract}

Conclusions: Our results show that both Ae. albopictus and Ae. aegypti, from Reunion Island, are more likely to be competent for ZIKV in contrast to CX. quinquefasciatus which appeared refractory to all tested ZIKV strains. This improves our understanding of the role of mosquito species in the risk of the ZIKV emergence on Reunion Island.

Keywords: Flavivirus, Mosquito vectors, Vector competence, Reunion Island

\section{Background}

During the last decades, several mosquito-borne viruses belonging to the families Togaviridae, Phenuiviridae and Flaviviridae have (re)emerged around the world

*Correspondence: yann.gomard@gmail.com; patrick.mavingui@cnrs.fr UMR PIMIT (Processus Infectieux en Milieu Insulaire Tropical), Université de La Réunion, INSERM 1187, CNRS 9192, IRD 249, Plateforme

Technologique CYROI, Sainte-Clotilde, La Réunion, France with consequences for the health of human and animal populations [1]. This is, for example, the case of the Zika virus (ZIKV), an emerging flavivirus (family Flaviviridae), responsible for large outbreaks in human populations in many countries [2]. Zika virus was first isolated in 1947 from a sentinel rhesus monkey in the Zika Forest (Uganda) and then from Aedes africanus mosquitoes in 1948 [3]. Before its global expansion, this virus has received little attention and remained less studied. In

c) The Author(s) 2020. This article is licensed under a Creative Commons Attribution 4.0 International License, which permits use, sharing, adaptation, distribution and reproduction in any medium or format, as long as you give appropriate credit to the original author(s) and the source, provide a link to the Creative Commons licence, and indicate if changes were made. The images or other third party material in this article are included in the article's Creative Commons licence, unless indicated otherwise in a credit line to the material. If material is not included in the article's Creative Commons licence and your intended use is not permitted by statutory regulation or exceeds the permitted use, you will need to obtain permission directly from the copyright holder. To view a copy of this licence, visit http://creativeco mmons.org/licenses/by/4.0/. The Creative Commons Public Domain Dedication waiver (http://creativecommons.org/publicdomain/ zero/1.0/) applies to the data made available in this article, unless otherwise stated in a credit line to the data. 
2007, the first ZIKV outbreak was reported in the Yap Islands (Federated States of Micronesia) where 7381 inhabitants ( $73 \%$ of the population) were estimated to be infected [4]. Thereafter, in 2013-2015 a large ZIKV outbreak was reported in French Polynesia, where about 28,000 human cases were recorded [5]. In 2015, the virus reached Brazil and rapidly spread across the Americas where hundreds of thousands of individuals were infected [6]. In humans, symptomatic ZIKV infections are selflimiting acute febrile disease with symptoms ranging from rash, fever, headache and myalgia [7-9]. However, more severe symptoms including microcephaly in newborns and young children and Guillain-Barré Syndrome may occur $[6,10]$. Genetic analyses have shown that global ZIKV strains belong to three genotypes; Asian, West African (Nigerian cluster) and East African (MR766 prototype cluster) [11]. The viral strains involved in all major international ZIKV outbreaks belong to the Asian genotype [11-14].

ZIKV has been detected in field isolates of many mosquito genera including Anopheles, Aedes, Culex, Eretmapodites and Mansonia, and vector competence experiments in laboratory conditions have been performed using mosquitoes from the genera Anopheles, Aedes and Culex [15, 16]. According to these studies, Aedes aegypti is considered to be the main vector of ZIKV [16] but other Aedes species such as Aedes albopictus or Aedes polynesiensis also play a role in ZIKV transmission $[17,18]$. Conversely, many studies showed that the mosquito species Culex pipiens and Culex quinquefasciatus play no role in ZIKV transmission [19-29]. As reported for other arboviruses (see [30] for review), the vector competence for ZIKV varies between mosquito strains and ZIKV genotypes [31-34]. For instance, Aubry et al. [35] showed that African Ae. aegypti are less susceptible than non-African Ae. aegypti to Asian and African ZIKV infections. Similarly, the vector competence of Ae. albopictus for ZIKV strains also depends on the geographical origin of field-derived mosquito populations [33, 36]. Therefore, to better evaluate the role of mosquito vectors in the transmission dynamics of arboviruses in the field, it is essential to integrate different genetic variants of both mosquitoes and viruses in the examination of vector competence.

Reunion Island is an overseas French territory located in the South-Western Indian Ocean (SWIO), $700 \mathrm{~km}$ East of Madagascar. Twelve mosquito species (belonging to four genera: Aedes, Anopheles, Culex and Orthopodomyia) are currently recognized on the island [37] but $A e$. albopictus and $C x$. quinquefasciatus are the most abundant mosquitoes and are commonly found all over the island in urban, peri-urban and rural areas, sometimes reaching $1200-1400 \mathrm{~m}$ of altitude [37]. Aedes aegypti is also present on Reunion Island but its geographical distribution is restricted to a few local sites [37]. In 20052006, Reunion Island experienced a chikungunya virus (CHIKV) outbreak that was responsible for more than 250,000 human cases [38]. More recently, an epidemic of dengue virus (DENV) started at the end of 2017 was responsible for more than 25,000 autochthonous human cases on the island at the beginning of 2020 [39, 40]. Regarding ZIKV, although a small number of imported human cases have been reported, no autochthonous transmission has been recorded to date on Reunion Island. Previous investigations of vector competence for ZIKV involving mosquitoes from Reunion Island, only focused on Ae. albopictus and Asian ZIKV strains, reported no transmission capacity of the mosquito strains tested [41, 42].

In the present study, we examined the vector competence of three mosquito species from Reunion Island, namely Ae. albopictus, Ae. aegypti and Cx. quinquefasciatus, for one African and two Asian ZIKV strains. The results of this investigation may help to better estimate the risk of the ZIKV emergence on Reunion Island.

\section{Methods \\ Mosquito samples}

Three mosquito species from Reunion Island were used to evaluate vector competence for ZIKV: Ae. albopictus; Ae. aegypti; and Cx. quinquefasciatus. Mosquitoes were sampled as eggs (for Ae. albopictus) or larvae and pupae (for Cx. quinquefasciatus) in four locations in 2019 (Fig. 1). Field samples were transported to the insect laboratory where they were reared to adulthood. For Ae. aegypti, a strain collected in 2014 (in the location Trois Bassins, see Fig. 1) and maintained in an insectary was used. Mosquitoes were reared under standard conditions at $26 \pm 1{ }^{\circ} \mathrm{C}$ and $80 \%$ relative humidity $(\mathrm{RH})$ with a $12 \mathrm{~h}$ light $/ 12 \mathrm{~h}$ dark photoperiod. Larvae were supplied every two days with yeast tablets and adults were fed with $10 \%$ sucrose solution. Experimental infections were performed using 5 mosquito strains: 2 strains of $A e$. albopictus $\left(\mathrm{F}_{0}\right.$ generations); 1 strain of Ae. aegypti $\left(\mathrm{F}_{27}\right.$ generation); and 2 strains of $C x$. quinquefasciatus $\left(\mathrm{F}_{0}\right.$ and $\mathrm{F}_{1}$ generations).

\section{Viral strains}

We used three ZIKV strains, namely Dak84 (GenBank: KU955592, African lineage), MAS66 (GenBank: KX694533, Asian lineage) and PaRi_2015 (GenBank: KU647676, Asian lineage) provided as lyophilizates by the European Virus Archive goes global (EVAg). The Dak84 strain was originally isolated in 1984 from Aedes taylori in Senegal and passaged four times on BHK21 cells. The MAS66 strain was isolated in 1966 from Ae. 


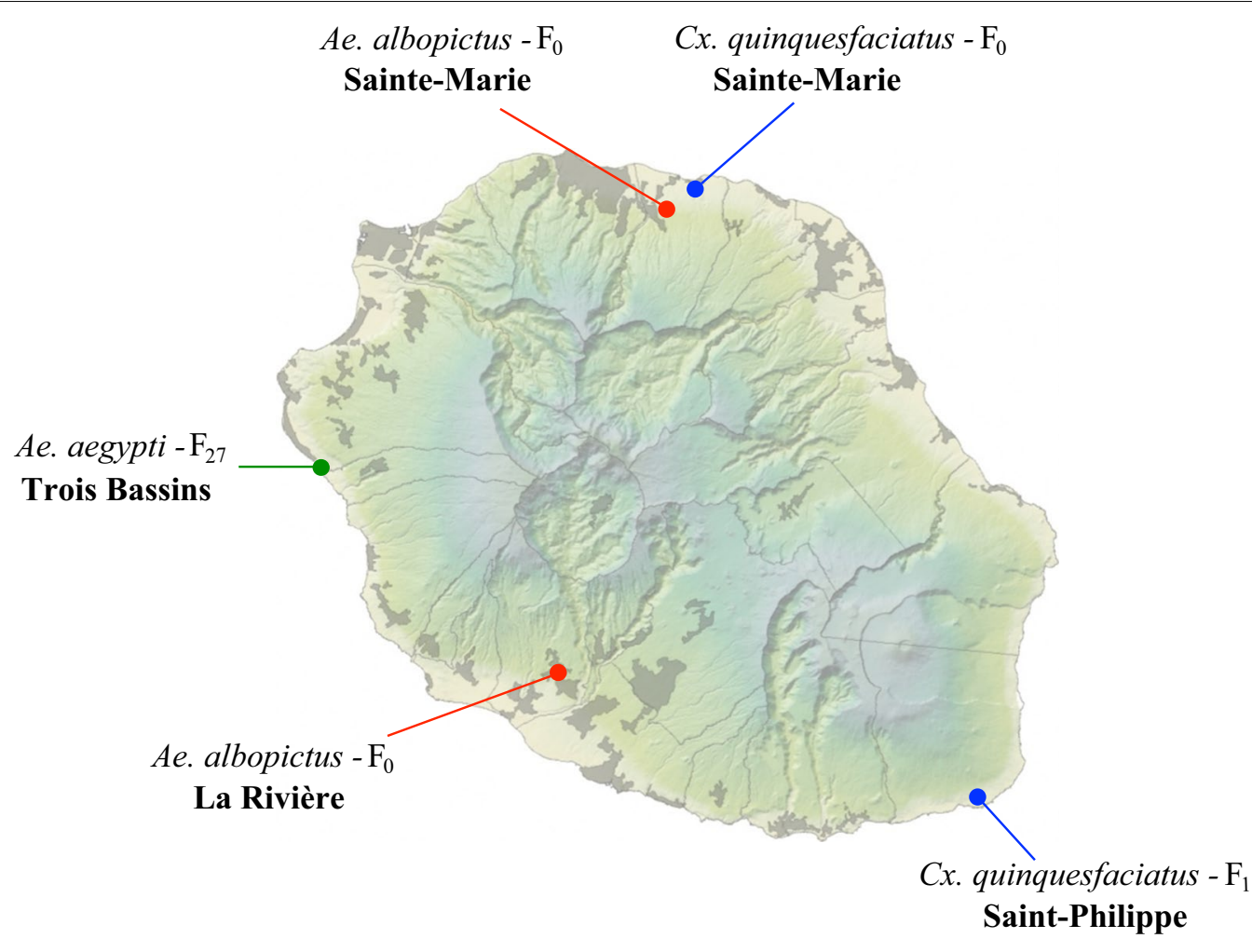

$20 \mathrm{~km}$

Fig. 1 Map of sampling sites were mosquitoes were collected in Reunion Island. Red, green and blue points indicate the locations where Aedes albopictus, Aedes aegypti and Culex quinquesfasciatus strains were collected, respectively

aegypti from Malaysia and passaged four times on Vero cells. The PaRi_2015 strain was isolated from human serum in Martinique in 2015 and passaged three times on Vero cells. Before viral production, lyophilizates were resuspended into $200 \mu \mathrm{l}$ to $400 \mu \mathrm{l}$ distilled water. All viruses were subsequently amplified in Vero E6 cells (ATCC, ref. CRL-1586) at a MOI of 0.1 in an Eagle's minimum essential medium (MEM) supplemented with $2 \%$ heat-inactivated foetal bovine serum (FBS), $2 \mathrm{mmol} / \mathrm{l} \mathrm{L}$-glutamine, $1 \mathrm{mmol} / \mathrm{l}$ sodium pyruvate, $10 \mathrm{U} / \mathrm{ml}$ of penicillin, $0.1 \mathrm{mg} /$ $\mathrm{ml}$ of streptomycin and $0.5 \mu \mathrm{g} / \mathrm{ml}$ of fungizone (PAN Biotech, Aidenbach, Germany). Vero cells were maintained at $37{ }^{\circ} \mathrm{C}$ with a $5 \% \mathrm{CO}_{2}$ atmosphere. For all virus stocks, supernatants were harvested 2 days post-infection and then frozen at $-80{ }^{\circ} \mathrm{C}$ until use. The final titers of our ZIKV stocks were $10^{7.4} \mathrm{PFU} / \mathrm{ml}, 10^{5.8} \mathrm{PFU} / \mathrm{ml}$ and $10^{6.9}$ $\mathrm{PFU} / \mathrm{ml}$ for Dak84, MAS66 and PaRi_2015, respectively.

\section{Oral infections of mosquitoes}

Seven to 10-day-old female mosquitoes were isolated in plastic boxes and transferred into a climatic chamber $\left(26 \pm 1{ }^{\circ} \mathrm{C} ; 80 \% \mathrm{RH} ; 12 \mathrm{~h}\right.$ light/12 h dark photoperiod) where they were starved for $48 \mathrm{~h}$. After this starvation period, mosquitoes were fed with a blood meal containing $1.4 \mathrm{ml}$ of washed rabbit erythrocytes, $700 \mu \mathrm{l}$ of ZIKV containing culture supernatant from the strain of interest and $5 \mathrm{mM}(21 \mu \mathrm{l})$ adenosine triphosphate (ATP) as phagostimulant. The titers of ZIKV in the blood preparations were $10^{6.85} \mathrm{PFU} / \mathrm{ml}, 10^{5.3} \mathrm{PFU} / \mathrm{ml}$ and $10^{6.3} \mathrm{PFU} /$ $\mathrm{ml}$ for Dak84, MAS66 and PaRi_2015, respectively. The blood preparations containing ZIKV were provided to mosquitoes using a Hemotek feeding system (Hemotek Limited, Great Harwood, UK) with pig intestine as the membrane. After $30 \mathrm{~min}$ to $1 \mathrm{~h}$ of feeding, fully engorged females were transferred into a climatic chamber where they were maintained with $10 \%$ sucrose for 21 days.

\section{Mosquito processing}

At 14 and 21 days post-infection (dpi), saliva was collected from individual mosquitoes ( $n=10$ to 33$)$ using a forced salivation method [43] that allows saliva to be collected by removing the legs and wings of each mosquito and then inserting the proboscis into a $20 \mu \mathrm{l}$ pipette tip containing $5 \mu \mathrm{l}$ of FBS. After $45 \mathrm{~min}$, the resulting solution containing the saliva was mixed with $45 \mu \mathrm{l}$ of MEM supplemented with $2 \mathrm{mmol} / \mathrm{l} \mathrm{L}$-glutamine, $1 \mathrm{mmol} / \mathrm{l}$ 
sodium pyruvate, $10 \mathrm{U} / \mathrm{ml}$ of penicillin, $0.1 \mathrm{mg} / \mathrm{ml}$ of streptomycin and $0.5 \mu \mathrm{g} / \mathrm{ml}$ of fungizone. Afterwards, the head and the body of each specimen were ground separately in $300 \mu \mathrm{l}$ of the same MEM medium but supplemented with $2 \%$ FBS and centrifuged at $10,000 \times g$ for 5 min to pellet tissue debris. Finally, $200 \mu \mathrm{l}$ of the supernatant of each sample was stored at $-80{ }^{\circ} \mathrm{C}$ until viral detection and titration.

\section{Virus detection, titration and vector competence evaluation}

Plaque forming unit assays were used to determine the ZIKV infection status of bodies, heads and saliva. For this, Vero cells were seeded the previous day in 12-well culture plates at a density of $3 \times 10^{5}$ cells per well. Cells were infected with $250 \mu \mathrm{l}$ of ten-fold dilutions of body, head homogenates or saliva. After an incubation of $2 \mathrm{~h}$ at $37{ }^{\circ} \mathrm{C}$ with a $5 \% \mathrm{CO}_{2}$ atmosphere, $1 \mathrm{ml}$ of MEM supplemented with $5 \%$ of FBS, $2 \mathrm{mmol} / \mathrm{l}$ L-glutamine, 1 $\mathrm{mmol} / \mathrm{l}$ sodium pyruvate, $10 \mathrm{U} / \mathrm{ml}$ of penicillin, $0.1 \mathrm{mg} /$ $\mathrm{ml}$ of streptomycin, $0.5 \mu \mathrm{g} / \mathrm{ml}$ of fungizone and $0.8 \%$ carboxymethylcellulose sodium salt (CMC; Sigma-Aldrich, Saint-Quentin-Fallavier, France) was added in each well and cells were incubated for 7 days at $37{ }^{\circ} \mathrm{C}$ with a $5 \%$ $\mathrm{CO}_{2}$ atmosphere. Thereafter, the medium was removed, and cells were fixed with $3.7 \%$ paraformaldehyde (SigmaAldrich). Finally, cells were stained with $0.5 \%$ crystal violet (Sigma-Aldrich) diluted in 20\% ethanol.

The vector competence of each mosquito strain for the three ZIKV strains was evaluated using samples collected only at 14 and $21 \mathrm{dpi}$ as previous investigations have shown higher dissemination and transmission values from day $14[17,23,44]$. Three parameters were then examined: the infection rate (IR); the dissemination efficiency (DE); and the transmission efficiency (TE). The IR corresponds to the proportion of infected bodies (abdomen and thorax) among the total number of mosquitoes tested; the DE is the proportion of mosquitoes with ZIKV infected heads among all blood-fed females and the TE was calculated as the proportion of females with ZIKV in the saliva among the total number of mosquitoes tested.

\section{Statistical analysis}

Fisher's exact test was used to compare IR, DE and TE parameters for each dpi between mosquito strains for a given ZIKV strain. For multiple comparisons the Bonferroni correction was applied [45]. The Kruskal-Wallis test was used to compare viral loads in bodies, heads and saliva for each dpi between mosquito strains or species for a given ZIKV strain. All statistical analyses were performed in R software (v.3.6.2) [46] with the FSA [47], RVAideMemoire [48] and stats [46] packages.

\section{Results}

Mosquito strains of Ae. albopictus, Ae. aegypti and $C x$. quinquesfasciatus from Reunion Island were orally exposed to one African ZIKV strain (Dak84) and two Asian strains (PaRi_2015 and MAS66). We were unable to increase the titers of viral stocks by cell culture, therefore we fed each mosquito strain with the maximum possible virus titer, which differed between strains (i.e. $10^{6.85} \mathrm{PFU} / \mathrm{ml}, 10^{5.3} \mathrm{PFU} / \mathrm{ml}$ and $10^{6.3} \mathrm{PFU} / \mathrm{ml}$ for Dak84, MAS66 and PaRi_2015, respectively).

When infected with the ZIKV strain MAS66, no infectious ZIKV was detected in the bodies, the heads or the saliva of the two Cx. quinquefasciatus strains either at 14 or 21 dpi. Only one Ae. albopictus specimen out of 64 individuals from the location Sainte-Marie was able to be infected, to disseminate and to transmit MAS66 at 21 days with a viral titer of $6.48 \log _{10}$ PFU, $6.35 \log _{10}$ PFU and $1.52 \log _{10}$ PFU detected in the body, the head and the saliva, respectively. The Ae. aegypti strain also showed a low susceptibility to MAS66 as infectious viral particles were only detected in the body of one specimen among 32 individuals at $14 \mathrm{dpi}$ (viral load of $8.08 \log _{10}$ PFU/ body).

Vector competence analysis of the three mosquito species infected with the ZIKV strain PaRi_2015 showed no infection, dissemination or transmission for $C x$. quinquefasciatus and Ae. albopictus. For Ae. aegypti, a limited number of specimens were able to replicate the ZIKV strain PaRi_2015. The values of IRs were $12.5 \%(n=4)$ and $6.3 \%(n=2)$ at 14 and $21 \mathrm{dpi}$, respectively (mean viral loads \pm SD: $5.72 \pm 0.36 \log _{10}$ PFU/body and $5.59 \pm 0.24$ $\log _{10}$ PFU/body at 14 and $21 \mathrm{dpi}$, respectively); DEs of $9.4 \%(n=3)$ and $6.3 \%(n=2)$ at 14 and $21 \mathrm{dpi}$, respectively (mean viral loads: $4.73 \pm 1.10 \log _{10}$ PFU/head and $5.03 \pm 0.15 \log _{10}$ PFU/head at 14 and $21 \mathrm{dpi}$, respectively) and TEs of $3.1 \%(n=1)$ at both 14 and $21 \mathrm{dpi}\left(2.30 \log _{10}\right.$ $\mathrm{PFU} /$ saliva and $1.82 \log _{10} \mathrm{PFU} /$ saliva at 14 and $21 \mathrm{dpi}$, respectively).

The highest vector competence parameters were observed for the African ZIKV strain Dak84 from Ae. albopictus and Ae. aegypti, while Cx. quinquefasciatus mosquitoes were unable to be infected, to disseminate or to transmit Dak84 as observed with the two Asian ZIKV strains. For Ae. albopictus, the IRs were quite similar between the two mosquito strains at $14 \mathrm{dpi}(78.1 \%$ and $68.8 \%$ for Sainte-Marie and La Rivière, respectively; Fig. 2a) and $21 \mathrm{dpi}$ (75.0\% and $68.8 \%$ for Sainte-Marie and La Rivière, respectively; Fig. 2a). Likewise, similar results were observed for DEs with $62.5 \%$ and $50.0 \%$ at $14 \mathrm{dpi}$ and $71.9 \%$ and $62.5 \%$ at $21 \mathrm{dpi}$ for Sainte-Marie and La Rivière strains, respectively (Fig. 2b). The comparison of the TEs between the two Ae. albopictus strains revealed lower values for mosquitoes from La Rivière 

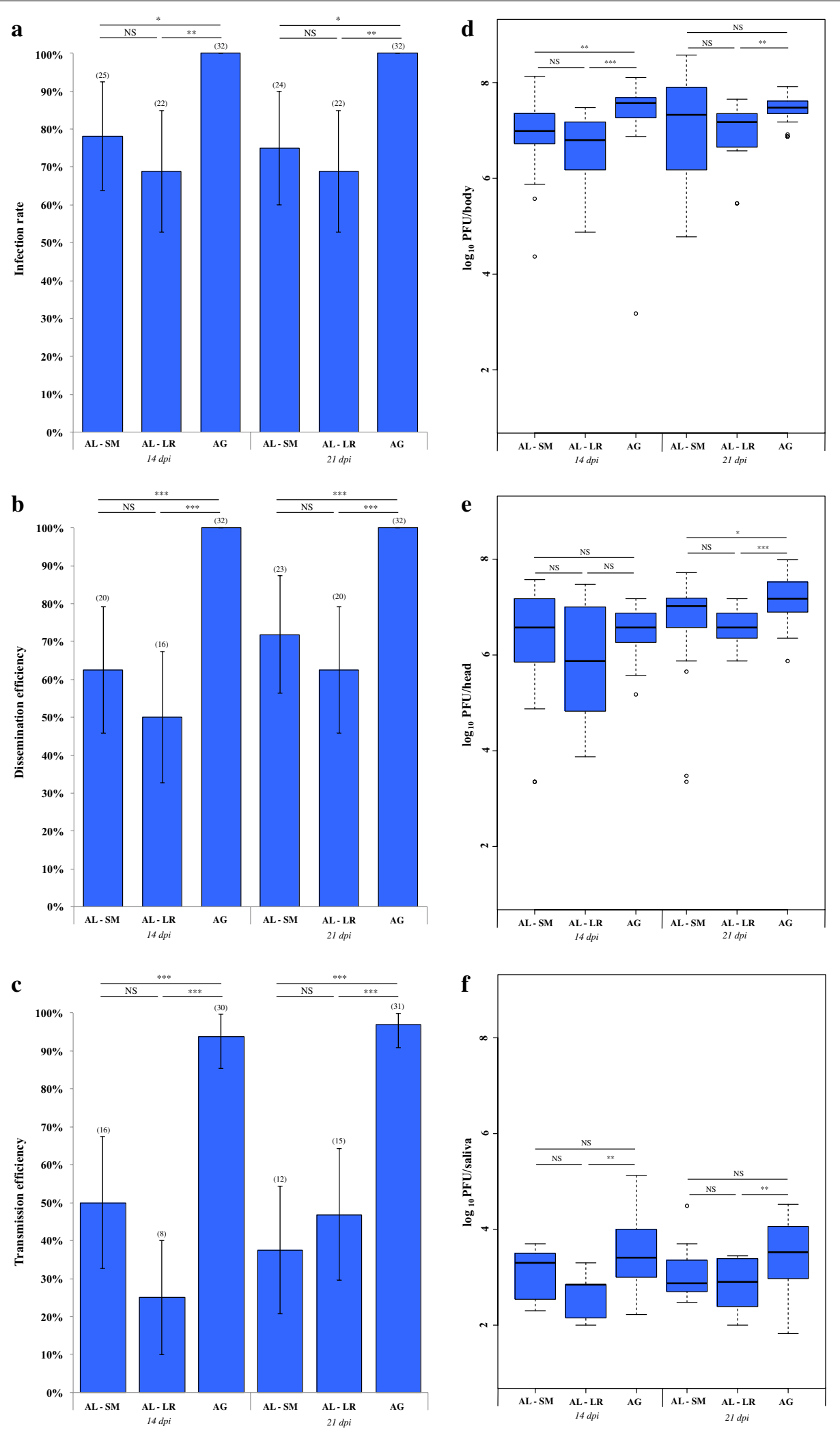
(See figure on previous page.)

Fig. 2 Vector competence parameters of Aedes albopictus and Aedes aegypti strains from Reunion Island infected with the African ZIKV strain Dak84 (infectious blood-meal viral titer of $10^{6.85} \mathrm{PFU} / \mathrm{ml}$ ). At 14 and 21 days after the infection, mosquitoes were examined for the presence of infectious viral particles detected by titration on Vero cells. The graphics $\mathbf{a}-\mathbf{c}$ correspond to infection rate (IR), dissemination efficiency (DE) and transmission efficiency (TE), respectively. The graphics $\mathbf{d}-\mathbf{f}$ correspond to viral loads in bodies, heads and saliva, respectively. The numbers in parentheses indicate the number of positive samples (samples with infectious ZIKV particles). The error bars correspond to the $95 \%$ confidence interval. The asterisks indicate the level of significance of differences (NS: no significant difference; ${ }^{*} P<0.05$; ${ }^{*} P<0.01$; ${ }^{* * *} P<0.001$ ) obtained from Fisher's exact tests (for infection rates, dissemination and transmission efficiencies) and Kruskal-Wallis tests (for viral loads in bodies, heads and saliva). Abbreviations: AG, Ae. aegypti; AL, Ae. albopictus; SM, Sainte-Marie; LR, La Rivière

at 14 dpi $(25.0 \%$ for La Rivière versus $50.0 \%$ for SainteMarie), while the TE of La Rivière was higher than that of Sainte-Marie at $21 \mathrm{dpi}(46.9 \%$ and $37.5 \%$ for La Rivière and Sainte-Marie, respectively). However, no significant differences were detected between the two Ae. albopictus strains for either TEs, IRs or DEs (Fisher's exact test: all $P>0.05)$. Similarly, no significant differences were detected between the two mosquito strains for the viral loads in bodies (Kruskal-Wallis H-test: $\chi^{2}=2.845, d f=1$, $P=0.092$ at $14 \mathrm{dpi}$ and $\chi^{2}=0.779, d f=1, P=0.377$ at $21 \mathrm{dpi}$ ), heads (Kruskal-Wallis H-test: $\chi^{2}=1.053, d f=1$, $P=0.305$ at $14 \mathrm{dpi}$ and $\chi^{2}=1.963, d f=1, P=0.161$ at 21 dpi) and saliva (Kruskal-Wallis H-test: $\chi^{2}=4.603, d f=1$, $P=0.032$ at $14 \mathrm{dpi}$ and $\chi^{2}=1.108, d f=1, P=0.293$ at $21 \mathrm{dpi}$ ) (Fig. 2d-f). For Ae. aegypti, all individuals were infected and were able to disseminate Dak84 at 14 and $21 \mathrm{dpi}(\mathrm{IRs}=100.0 \%$ and DEs $=100.0 \%$ ) (Fig. 2a, b). In addition, almost all individuals were able to transmit Dak84 (TEs of $93.8 \%$ and $96.9 \%$ at 14 and $21 \mathrm{dpi}$, respectively) (Fig. 2c). For this African ZIKV strain, in bodies, the mean viral loads were $7.36 \pm 0.81 \log _{10}$ PFU/body and $7.41 \pm 0.30 \log _{10}$ PFU/body at 14 and $21 \mathrm{dpi}$, respectively. In heads, the mean viral loads were $6.51 \pm 0.51$ $\log _{10}$ PFU/head and $6.61 \pm 0.35 \log _{10}$ PFU/head at 14 and $21 \mathrm{dpi}$, respectively. In saliva, the mean viral loads were $3.47 \pm 0.72 \log _{10}$ PFU/saliva and $3.45 \pm 0.70 \log _{10}$ PFU/ saliva at 14 and $21 \mathrm{dpi}$, respectively (Fig. $2 \mathrm{~d}-\mathrm{f}$ ).

When comparing vector competence parameters of $A e$. aegypti and Ae. albopictus infected with Dak84, the IRs, DEs and TEs were significantly higher in Ae. aegypti than in Ae. albopictus (Fisher's exact test: all; $P<0.05$ for IRs, DEs and TEs at 14 and $21 \mathrm{dpi}$ ) (Fig. 2a-c). Similarly, $A e$. aegypti displayed significantly higher viral loads in bodies at 14 dpi (Kruskal-Wallis H-test: $\chi^{2}=22.315, d f=1$, $P<0.001)$ and 21 dpi (Kruskal-Wallis H-test: $X^{2}=6.933$, $d f=1, P=0.008$ at $21 \mathrm{dpi}$ ), in heads at $21 \mathrm{dpi}$ (KruskalWallis H-test: $\left.\chi^{2}=14.897, d f=1, P<0.001\right)$, and in saliva at 14 dpi (Kruskal-Wallis H-test: $X^{2}=6.098, d f=1$, $P=0.014$ ) and $21 \mathrm{dpi}$ (Kruskal-Wallis H-test: $\chi^{2}=8.512$, $d f=1, P=0.004$ at $21 \mathrm{dpi}$ ) (Fig. $2 \mathrm{~d}-\mathrm{f}$ ). However, no significant difference in viral loads in heads at 14 dpi was detected between the two mosquito species (KruskalWallis H-test: $\chi^{2}=0.382 d f==1, P=0.537$ ).

\section{Discussion}

In the present study, we evaluated the vector competence of three mosquito species from Reunion Island including Ae. albopictus, Ae. aegypti and Cx. quinquefasciatus for three ZIKV strains: one African strain (Dak84) and two Asian strains (PaRi_2015 and MAS66). We showed that $C x$. quinquefasciatus mosquitoes were unable to be infected, to disseminate or to transmit the three ZIKV strains, a result also reported by Hery et al. [23] using $C x$. quinquefasciatus mosquitoes from Guadeloupe tested against the same three ZIKV strains. Our results are also consistent with other studies showing that $C x$. quinquefasciatus from different geographical origins, as well as its sibling species $C x$. pipiens, are not able to transmit ZIKV [19-29]. This refractoriness against ZIKV does not seem to be related to an RNA interference (RNAi) mechanism or to the presence of the endosymbiotic bacterium $\mathrm{Wol}$ bachia [20]. However, it could be explained by other antiviral immune responses in the midgut that block virus replication [49] or the absence of specific cell receptors for attachment of ZIKV on midgut epithelial cells [50]. Ultimately, our results suggest that $C x$. quinquefasciatus would not be a vector of ZIKV on Reunion Island.

The Ae. albopictus and Ae. aegypti strains from Reunion Island were poorly competent for the two Asian ZIKV strains at the viral titers tested. Indeed, for $A e$. albopictus, no infectious viral particle was detected with the PaRi_2015 strain and only one specimen was able to transmit the MAS66 strain. In contrast, mosquitoes from the two tested Ae. albopictus strains were more susceptible to the African ZIKV Dak84 strain (IRs, DEs and TEs up to $78.1 \%, 62.5 \%$ and $50.0 \%$, respectively). The results obtained for Ae. aegypti were quite similar to those of Ae. albopictus with no transmission for MAS66, only two positive saliva for PaRi_2015, and higher transmission efficiencies with Dak84 (TEs of $93.8 \%$ and $96.9 \%$ at 14 and $21 \mathrm{dpi}$, respectively). Such a difference in vector competence of Ae. albopictus and Ae. aegypti between Asian and African ZIKV strains could be explained by virus titers used in infectious blood meals. Indeed, lower titers were used for the two Asian ZIKV strains $\left(10^{5.3} \mathrm{PFU} / \mathrm{ml}\right.$ and $10^{6.3} \mathrm{PFU} / \mathrm{ml}$, respectively for MAS66 and PaRi_2015) as compared to Dak84 with $10^{6.85} \mathrm{PFU} /$ 
$\mathrm{ml}$; and the effects of blood-meal titers in the outcomes of vector competence analyses involving ZIKV strains have been previously demonstrated [51, 52]. Despite this caveat, several studies also described low transmission rates of Asian ZIKV strains by Aedes mosquitoes, even using higher virus titers. For Reunion Ae. albopictus, no viral transmission was detected using Asian ZIKV strains from New Caledonia (NC-2014-5132, virus titer of $10^{7} \mathrm{TCDI}_{50} / \mathrm{ml}$ ) [41] or from Suriname (SL1602, virus titers of $7.5 \times 10^{6} \mathrm{FFU} / \mathrm{ml}$ and $3 \times 10^{6} \mathrm{FFU} / \mathrm{ml}$ ) [42]. On the contrary, other studies have reported relatively high transmission efficiencies of Asian ZIKV strains using mosquito strains with different geographical origins. For instance, vector competence experiments have demonstrated the transmission of the ZIKV strains NC-20145132 and SL1602 by Ae. albopictus strains from Africa, America and France [31, 44, 53]. For Ae. aegypti, low susceptibility to Asian ZIKV strains has also been reported $[17,32,44]$ whereas higher transmission efficiencies were achieved from an Ae. aegypti strain from Guadeloupe (TEs of $12 \%$ for infection with MAS66 and PaRi_2015) [23] and from French Polynesia (TE of $17 \%$ for the ZIKV strain NC-2014-5132) [17]. Taken together, this supports the idea that vector competence of Aedes mosquitoes is population- and ZIKV strain-dependent. Some mosquito strains are competent to transmit ZIKV while others are poorly competent or cannot transmit the virus [17, 23, 26, 31-33, 41, 44, 54-59].

The role of mosquito-ZIKV interaction in the outcome of vector competence is also illustrated by the African ZIKV strain. Indeed, when comparing our results with those of Hery et al. [23] we obtained higher TEs from an equivalent titer of the Dak84 strain for Ae. aegypti mosquitoes from Reunion (mean TE $>90 \%$ ) than reported for Ae. aegypti from Guadeloupe (mean $\mathrm{TE}=50 \%$ ). Differences were also observed with viral loads in saliva with higher viral concentrations in mosquitoes from Reunion Island (mean viral load of $3.47 \pm 0.72 \log _{10}$ PFU/saliva and $3.45 \pm 0.70 \log _{10}$ PFU/saliva at 14 and $21 \mathrm{dpi}$, respectively) as compared to those from Guadeloupe (mean viral concentration inferior to $2.0 \log _{10}$ PFU/saliva) [23]. Such contrasting results between the two studies could be explained by the laboratory colonization, with a laboratory Ae. aegypti strain of several generations $\left(\mathrm{F}_{27}\right.$ generation) for our study versus a $F_{1}$ mosquito strain for Hery et al. [23]. Other factors affecting the outcomes of vector competence such as the temperature [60] and feeding conditions [34] could also explain these differences.

Finally, although we used different virus titers for Asian and African ZIKV strains, both Reunion Ae. albopictus and Ae. aegypti appeared more able to transmit the African ZIKV strain. This result is consistent with previous investigations showing that even with similar titers of ZIKV strains in infectious blood meals, African ZIKV strains are more efficiently transmitted by mosquitoes than Asian strains [18, 32-34, 36].

\section{Conclusions}

Our results showed that $C x$. quinquefasciatus from Reunion Island is refractory to ZIKV infection. In contrast, Ae. albopictus and Ae. aegypti from Reunion Island showed low vector competence for Asian ZIKV strains and displayed high transmission efficiencies for the African ZIKV. Moreover, we found that $A e$. aegypti was a modestly more efficient vector for the African ZIKV strain than Ae. albopictus which is consistent with a recent study conducted in Central Africa with the Dak84 ZIKV strain [61]. However, on Reunion Island, Ae. albopictus is far more abundant than $A e$. aegypti and therefore may play a more significant role in ZIKV transmission even in light of the differential vector competence. Future studies should also consider potential mutations in the viral genome that can change the vector competence, as was reported for CHIKV where a single substitution was associated with better dissemination by Ae. albopictus [62, 63].

\section{Abbreviations}

CHIK: Chikungunya virus; DE: Dissemination efficiency; DENV: Dengue virus; Dpi: Days post-infection; MEM: Eagle's minimum essential medium; FBS: Foetal bovine serum; IR: Infection rate; RH: Relative humidity; TE: Transmission efficiency; ZIKV: Zika virus.

\section{Acknowledgements}

We are very grateful to the members of the TIS team (MIVEGEC/RDD) from Reunion Island (Gilbert Le Goff, Benjamin Gaudillat, Nausicaa Habchi-Hanriot, David Benjamin, Lucie Marquereau and Louis-Clément Gouagna) who have provided to us the laboratory Ae. aegypti line and Ae. albopictus from Sainte-Marie. We are grateful to Sarah Hafsia and Céline Toty (UMR PIMIT) for their help in the rearing of mosquitoes. We also thank David Wilkinson (UMR PIMIT) for exchanges concerning the scientific content and use of the English language in the paper

\section{Authors' contributions}

CA and PM designed the research. CL, CA and YG performed mosquitoes sampling in the field and carried out the rearing in the insect laboratory. CA and YG conducted experimental infections and performed virus detection and titration. YG analysed the data. YG, CA and PM wrote the paper. All authors read and approved the final manuscript.

\section{Funding}

This work was funded by the consortium ZIKAlliance project (European Union-Horizon 2020 programme) under grant agreement no. 735548 and the European Regional Development Funds (ERDF) PO INTERREG through VECTOBIOMES project, number RE0009962. YG was firstly supported by a postdoctoral fellowship provided by IRD (Institut de Recherche pour le Développement) and then by the VECTOBIOMES project.

\section{Availability of data and materials}

All data generated or analysed during this study are included in this published article. 


\section{Ethics approval and consent to participate}

For mosquito oral infection, the blood was obtained from rabbits. These rabbits were housed within the animal laboratory of Cyclotron Réunion Océan Indien (CYROI) based on Reunion Island. All experimental procedures were conducted in our BSL3 facility PLATIN-OI (for Plateau Infectiologie Océan Indien) and performed according to the guidelines for care and use of laboratory animals of European Council Directive 2010/63/EU approved by Ethic Committee of Reunion Island and registered under the reference APAFIS \#16365-2018020611417370 v4.

\section{Consent for publication}

\section{Not applicable.}

\section{Competing interests}

The authors declare that they have no competing interests.

Received: 9 March 2020 Accepted: 29 July 2020

Published online: 06 August 2020

\section{References}

1. Huang YJS, Higgs S, Vanlandingham DL. Emergence and re-emergence of mosquito-borne arboviruses. Curr Opin Virol. 2019:34:104-9.

2. Musso D, Gubler DJ. Zika virus. Clin Microbiol Rev. 2016;29:487-524.

3. Dick GWA, Kitchen SF, Haddow AJ. Zika virus (I). Isolations and serological specificity. Trans R Soc Trop Med Hyg. 1952;46:509-20.

4. Duffy MR, Chen TH, Hancock WT, Powers AM, Kool JL, Lanciotti RS, et al. Zika virus outbreak on Yap Island, Federated States of Micronesia. N. Engl J Med. 2009;360:2536-43.

5. Musso D, Nilles EJ, Cao-Lormeau VM. Rapid spread of emerging Zika virus in the Pacific area. Clin Microbiol Infect. 2014;20:0595-6.

6. Weaver SC, Costa F, Garcia-Blanco MA, Ko Al, Ribeiro GS, Saade G, et al Zika virus: history, emergence, biology, and prospects for control. Antiviral Res. 2016:130:69-80.

7. Sikka V, Chattu VK, Popli RK, Galwankar SC, Kelkar D, Sawicki SG, et al. The emergence of Zika virus as a global health security threat: a review and a consensus statement of the INDUSEM Joint Working Group (JWG). J Glob Infect Dis. 2016:8:3-15.

8. Plourde AR, Bloch EM. A literature review of Zika virus. Emerg Infect Dis. 2016;22:1185-92.

9. loos S, Mallet HP, Leparc Goffart I, Gauthier V, Cardoso T, Herida M. Current Zika virus epidemiology and recent epidemics. Med Mal Infect. 2014:44:302-7.

10. Cao-Lormeau VM, Blake A, Mons S, Lastère S, Roche C, Vanhomwegen J, et al. Guillain-Barré syndrome outbreak associated with Zika virus infection in French Polynesia: a case-control study. Lancet. 2016;387:1531-9.

11. Lanciotti RS, Lambert AJ, Holodniy M, Saavedra S, Signor del. CC. Phylogeny of Zika virus in western hemisphere, 2015. Emerg Infect Dis. 2016:22:933-5.

12. Campos GS, Bandeira AC, Sardi SI. Zika virus outbreak, Bahia, Brazil. Emerg Infect Dis. 2015;21:1885-6.

13. Dupont-Rouzeyrol M, O'Connor $\mathrm{O}$, Calvez $\mathrm{E}$, Daurès $\mathrm{M}$, John $\mathrm{M}$, Grangeon JP, et al. Co-infection with Zika and dengue viruses in 2 patients, New Caledonia, 2014. Emerg Infect Dis. 2015;21:381-2.

14. Cao-Lormeau VM, Roche C, Teissier A, Robin E, Berry AL, Mallet HP, et al. Zika virus, French Polynesia, South Pacific, 2013. Emerg Infect Dis. 2014;20:1085-6.

15. Epelboin Y, Talaga S, Epelboin L, Dusfour I. Zika virus: an updated review of competent or naturally infected mosquitoes. PLoS Negl Trop Dis. 2017;11:e0005933.

16. Gutiérrez-Bugallo G, Piedra LA, Rodriguez M, Bisset JA, Lourenço-deOliveira R, Weaver SC, et al. Vector-borne transmission and evolution of Zika virus. Nat Ecol Evol. 2019;3:561-9.

17. Calvez E, Mousson L, Vazeille M, O'Connor O, Cao-Lormeau VM, MathieuDaudé $F$, et al. Zika virus outbreak in the Pacific: vector competence of regional vectors. PLoS Negl Trop Dis. 2018;12:e0006637.

18. Vazeille M, Madec Y, Mousson L, Bellone R, Barré-Cardi H, Sousa CA, et al. Zika virus threshold determines transmission by European Aedes albopictus mosquitoes. Emerg Microbes Infect. 2019;8:1668-78.
19. Main BJ, Nicholson J, Winokur OC, Steiner C, Riemersma KK, Stuart J, et al. Vector competence of Aedes aegypti, Culex tarsalis, and Culex quinquefasciatus from California for Zika virus. PLoS Negl Trop Dis. 2018;12:e0006524

20. Lourenço-de-Oliveira R, Marques JT, Sreenu VB, Atyame Nten C, Aguiar ERGR, Varjak M, et al. Culex quinquefasciatus mosquitoes do not support replication of Zika virus. J Gen Virol. 2018;99:258-64.

21. Aliota MT, Peinado SA, Osorio JE, Bartholomay LC. Culex pipiens and Aedes triseriatus mosquito susceptibility to Zika virus. Emerg Infect Dis. 2016:22:1857-9.

22. Huang YJS, Ayers VB, Lyons AC, Unlu I, Alto BW, Cohnstaedt LW, et al. Culex species mosquitoes and Zika virus. Vector Borne Zoonotic Dis. 2016;16:673-6.

23. Hery L, Boullis A, Delannay C, Vega-Rúa A. Transmission potential of African, Asian and American Zika virus strains by Aedes aegypti and Culex quinquefasciatus from Guadeloupe (French West Indies). Emerg Microbes Infect. 2019;8:699-706.

24. Fernandes RS, Campos SS, Ferreira-de-Brito A, Miranda RM, Silva KAB, Castro MG, et al. Culex quinquefasciatus from Rio de Janeiro is not competent to transmit the local Zika virus. PLoS Negl Trop Dis. 2016;10:e0004993.

25. Amraoui F, Atyame-Nten C, Vega-Rúa A, Lourenço-de-Oliveira R, Vazeille $M$, Failloux AB. Culex mosquitoes are experimentally unable to transmit Zika virus. Euro Surveill. 2016;21:30333.

26. Liu Z, Zhou T, Lai Z, Zhang Z, Jia Z, Zhou G, et al. Competence of Aedes aegypti, Ae albopictus, and Culex quinquefasciatus mosquitoes as Zika virus vectors. China. Emerg Infect Dis. 2017;23:1085-91.

27. Duchemin JB, Mee PT, Lynch SE, Vedururu R, Trinidad L, Paradkar P. Zika vector transmission risk in temperate Australia: a vector competence study. Virol J. 2017;14:108.

28. Hart CE, Roundy CM, Azar SR, Huang JH, Yun R, Reynolds E, et al. Zika virus vector competency of mosquitoes, Gulf Coast, United States. Emerg Infect Dis. 2017;23:559-60.

29. Dodson BL, Rasgon JL. Vector competence of Anopheles and Culex mosquitoes for Zika virus. PeerJ. 2017:5:e3096.

30. Kramer LD. Complexity of virus-vector interactions. Curr Opin Virol. 2016:21:81-6.

31. Chouin-Carneiro T, Vega-Rua A, Vazeille M, Yebakima A, Girod R, Goindin D, et al. Differential susceptibilities of Aedes aegypti and Aedes albopictus from the Americas to Zika virus. PLoS Negl Trop Dis. 2016;10:e0004543.

32. Calvez E, O'Connor O, Pol M, Rousset D, Faye O, Richard V, et al. Differential transmission of Asian and African Zika virus lineages by Aedes aegypti from New Caledonia. Emerg Microbes Infect. 2018;7:159.

33. Azar SR, Roundy CM, Rossi SL, Huang JH, Leal G, Yun R, et al. Differential vector competency of Aedes albopictus populations from the Americas for Zika virus. Am J Trop Med Hyg. 2017;97:330-9.

34. Roundy CM, Azar SR, Rossi SL, Huang JH, Leal G, Yun R, et al. Variation in Aedes aegypti mosquito competence for Zika virus transmission. Emerg Infect Dis. 2017:23:625-32.

35. Aubry F, Martynow D, Baidaliuk A, Merkling SH, Dickson LB, Romero-Vivas $\mathrm{CM}$, et al. Worldwide survey reveals lower susceptibility of African Aedes aegypti mosquitoes to diverse strains of Zika virus. bioRxiv. 2018;342741.

36. McKenzie BA, Wilson AE, Zohdy S. Aedes albopictus is a competent vector of Zika virus: a meta-analysis. PLoS ONE. 2019;14:e0216794.

37. Boussès $P$, Dehecq JS, Brengues $C$, Fontenille D. Inventaire actualisé des moustiques (Diptera : Culicidae) de l'île de La Réunion, océan Indien. Bull Soc Pathol Exot. 2013;106:113-25.

38. Josseran L, Paquet C, Zehgnoun A, Caillere N, Le Tertre A, Solet JL, et al. Chikungunya disease outbreak, Reunion Island. Emerg Infect Dis. 2006:12:1994-5.

39. Pascalis H, Turpin J, Roche M, Krejbich P, Gadea G, Nten CA, et al. The epidemic of dengue virus type-2 cosmopolitan genotype on Reunion Island relates to its active circulation in the southwestern Indian Ocean neighboring islands. Heliyon. 2019;5:e01455.

40. Santé Publique France. Le point épidémio | Dengue à La Réunion | Point de situation 20/01/2020. https://www.santepubliquefrance.fr/regions/ ocean-indien/documents/bulletin-regional/2020/surveillance-de-ladenque-a-la-reunion.-point-au-20-janvier-2020. Accessed 06 Mar 2020.

41. Vazeille M, Dehecq JS, Failloux AB. Vectorial status of the Asian tiger mosquito Aedes albopictus of La Réunion Island for Zika virus. Med Vet Entomol. 2017:32:251-4. 
42. Lequime S, Dehecq JS, Briolant S, Fontaine A. European and tropical Aedes albopictus mosquito populations have similar systemic Zika virus infection dynamics. bioRxiv. 2019;764498.

43. Dubrulle M, Mousson L, Moutailler S, Vazeille M, Failloux AB. Chikungunya virus and Aedes mosquitoes: saliva is infectious as soon as two days after oral infection. PLOS ONE. 2009;4:e5895.

44. Jupille H, Seixas G, Mousson L, Sousa CA, Failloux AB. Zika virus, a new threat for Europe? PLoS Negl Trop Dis. 2016;10:e0004901.

45. Holm S. A simple sequentially rejective multiple test procedure. Scand J Stat. 1979;6:65-70.

46. R Development Core Team. R: A language and environment for statistical computing. Vienna: R Foundation for Statistical Computing. 2019. https:// www.R-project.org/.

47. Ogle D, Wheeler P, Dinno A. FSA: Fisheries stock analysis. R package version 0.8.26; 2019. https://github.com/droglenc/FSA.

48. Hervé M. RVAideMemoire: testing and plotting procedures for biostatistics. R package version 0.9-73. 2019. https://CRAN.R-project.org/packa ge= RVAideMemoire.

49. Sim S, Jupatanakul N, Dimopoulos G. Mosquito immunity against arboviruses. Viruses. 2014:6:4479-504.

50. Franz AWE, Kantor AM, Passarelli AL, Clem RJ. Tissue barriers to arbovirus infection in mosquitoes. Viruses. 2015;7:3741-67.

51. Ciota AT, Bialosuknia SM, Zink SD, Brecher M, Ehrbar DJ, Morrissette MN, et al. Effects of Zika virus strain and Aedes mosquito species on vector competence. Emerg Infect Dis. 2017;23:1110-7.

52. Weger-Lucarelli J, Rückert C, Chotiwan N, Nguyen C, Luna SMG, Fauver JR, et al. Vector competence of American mosquitoes for three strains of Zika virus. PLoS Negl Trop Dis. 2016;10:e0005101.

53. Amraoui F, Ayed WB, Madec Y, Faraj C, Himmi O, Btissam A, et al. Potential of Aedes albopictus to cause the emergence of arboviruses in Morocco. PLoS Negl Trop Dis. 2019;13:e0006997.

54. Luca MD, Severini F, Toma L, Boccolini D, Romi R, Remoli ME, et al. Experimental studies of susceptibility of Italian Aedes albopictus to Zika virus. Euro Surveill. 2016;21:30223.

55. Heitmann A, Jansen S, Lühken R, Leggewie M, Badusche M, Pluskota B, et al. Experimental transmission of Zika virus by mosquitoes from central Europe. Euro Surveill. 2017;22:30437.
56. Hugo LE, Stassen L, La J, Gosden E, Ekwudu O, Winterford C, et al. Vector competence of Australian Aedes aegypti and Aedes albopictus for an epidemic strain of Zika virus. PLoS Negl Trop Dis. 2019;13:e0007281.

57. Gutiérrez-López R, Bialosuknia SM, Ciota AT, Montalvo T, Martínez-de la Puente J, Gangoso L, et al. Vector competence of Aedes caspius and Ae. albopictus mosquitoes for Zika virus, Emerg Infect Dis. 2019;25:346-8.

58. González MA, Pavan MG, Fernandes RS, Busquets N, David MR, LourençoOliveira R, et al. Limited risk of Zika virus transmission by five Aedes albopictus populations from Spain. Parasit Vectors. 2019;12:150.

59. Hernández-Triana LM, Barrero E, Delacour-Estrella S, Ruiz-Arrondo I, Lucientes J, Fernández de Marco del M, et al. Evidence for infection but not transmission of Zika virus by Aedes albopictus (Diptera: Culicidae) from Spain. Parasit Vectors. 2019;12:204.

60. Onyango MG, Bialosuknia SM, Payne AF, Mathias N, Kuo L, Vigneron A, et al. Increased temperatures reduce the vectorial capacity of Aedes mosquitoes for Zika virus. Emerg Microbes Infect. 2020;9:67-77.

61. Kamgang B, Vazeille M, Tedjou A, Yougang AP, Wilson-Bahun TA, Mousson $L$, et al. Different populations of Aedes aegypti and Aedes albopictus (Diptera: Culicidae) from Central Africa are susceptible to Zika virus infection. PLoS Negl Trop Dis. 2020;14:e0008163.

62. Tsetsarkin KA, Vanlandingham DL, McGee CE, Higgs S. A single mutation in chikungunya virus affects vector specificity and epidemic potential. PLoS Pathog. 2007;3:e201.

63. Vazeille M, Moutailler S, Coudrier D, Rousseaux C, Khun H, Huerre M, et al. Two chikungunya isolates from the outbreak of La Reunion (Indian Ocean) exhibit different patterns of infection in the mosquito, Aedes albopictus. PLOS ONE. 2007;2:e1168.

\section{Publisher's Note}

Springer Nature remains neutral with regard to jurisdictional claims in published maps and institutional affiliations.
Ready to submit your research? Choose BMC and benefit from:

- fast, convenient online submission

- thorough peer review by experienced researchers in your field

- rapid publication on acceptance

- support for research data, including large and complex data types

- gold Open Access which fosters wider collaboration and increased citations

- maximum visibility for your research: over $100 \mathrm{M}$ website views per year

At BMC, research is always in progress.

Learn more biomedcentral.com/submissions 